\title{
Farklı Tuz Konsantrasyonlarında Semiz Otu (Portulaca oleracea) ve Kamışsı Yumak (Festuca arundinacea) Bitkileri Uygulanarak Tuzlu Toprakların Fitoremediasyon Yöntemiyle İyileştirilmesi
}

\author{
Hasan $\mathrm{Er}^{1,2^{*}}$, Semih Elibol ${ }^{3}$ \\ 1* Bingöl Üniversitesi, Ziraat Fakültesi, Biyosistem Mühendisliği Bölümü, Bingöl, Türkiye, (ORCID: 0000-0002-7880-8697), hasaner@bingol.edu.tr \\ ${ }^{2}$ Bingöl Üniversitesi, Arı ve Doğal Ürünler AR-GE ve ÜR-GE Uyg. ve Arş. Merkezi / Rektörlük, Bingöl, Türkiye (ORCID: 0000-0002-7880-8697), \\ hasaner@bingol.edu.tr \\ ${ }^{3}$ Bingöl Üniversitesi, Ziraat Fakültesi, Tarla Bitkileri Bölümü, Bingöl, Türkiye (ORCID: 0000-0001-5385-2571), selibol@bingol.edu.tr
}

(2nd International Conference on Applied Engineering and Natural Sciences ICAENS 2022, March 10-13, 2022)

(DOI: 10.31590 /ejosat.1069094)

ATIF/REFERENCE: Er, H., \& Elibol, S. (2022). Farklı Tuz Konsantrasyonlarında Semiz Otu (Portulaca oleracea) ve Kamışsı Yumak (Festuca arundinacea) Bitkileri Uygulanarak Tuzlu Toprakların Fitoremediasyon Yöntemiyle İyileştirilmesi. Avrupa Bilim ve Teknoloji Dergisi, (34), 70-74.

$\ddot{\mathbf{O z}}$

Tuzluluk tarımı olumsuz etkileyen en önemli çevresel faktörlerin başında gelmektedir. Tuzlu toprakların iyileştirilmesi maliyet ve yüksek iş gücü gerektirdiğinden dolayı fitoremediasyon alternatif bir yöntem olarak düşünülmektedir. Toprakta bulunan fazla tuzların bitkiler kullanılarak giderilmesi olarak ifade edilmektedir. Bu amaçla Semizotu (Portulaca oleracea) ve Kamışsı Yumak (Festuca arundinacea) bitkilerinin farklı tuz konsantrasyonlarında fitoremediasyon yöntemi ile değerlendirme potansiyeli araştırılmıştır. Çalışmada Toprak tuzluluğunu sağlamak amacıyla 4 farklı tuz $(\mathrm{NaCl})$ konsantrasyonu (0, 75, 150 ve 200 mM) uygulanmıştır. Araştırmada bitki boyu, bitki kuru ağırlığı ve yaş ağırlığı parametreleri ölçülmüştür. Hasad öncesi ve sonrası toprakta elektriksel iletkenlik (EC), değiş̧ebilir sodyum yüzdesi (ESP), katyon değişim kapasitesi (KDK) özellikleri incelenmiştir. bitki boyu, yaş ağırlığı ve kuru ağırlık değerlerine bakıldığında kamışsı yumak bitkisinin bitki boyu \%6.33 arttığı, bitki kuru ağırlığı \% 5.05 ve bitki yaş ağırlığı (\% 11.12) azaldığı görülmüştür. Semizotu bitkisinde ise bitki boyu \%39.1 azalmış, bitki yaş ve kuru ağırlığı \% 45 ve \% 42.11 artmıştır. İki farklı bitki grubundan oluşan çalışmada bitkilerin ekiminden önce ve hasatlarından sonra tuzlu toprakta EC, ESP ve KDK okumaları gerçekleştirilmiştir. Her iki bitkide de düşüş gözlemlenmiştir. Hesaplamalar neticesinde kamışsı yumak bitkisi, semiz otu bitkisine göre EC ve ESP değerlerini daha fazla azalttığı belirlenmiştir. KDK değerlerine bakıldığında bütün uygulamalar için önemli değişimlerin olmadığ hesaplanmıştır. Araştırma sonucunda her iki bitkininde tuzlu toprakların ıslahında kullanılan diğer yöntemlere ek olarak düşünülen fitoremediasyon yönteminde tercih edilebilecek bitkiler olarak görülebilmektedir.

Anahtar Kelimeler: Fitoremediasyon, Tuzlu topraklar, Portulaca oleracea, Festuca arundinacea, Yeşil 1slah

\section{Improvement of Salty Soils by Phytoremediation Method by Applying (Portulaca oleracea) and (Festuca arundinacea) Plants at Different Salt Concentrations}

\begin{abstract}
Salinity is one of the most important environmental factors affecting agriculture negatively. Phytoremediation is considered as an alternative method because of the high cost and labor requirement of remediation of saline soils. It is expressed as the removal of excess salts in the soil by using plants. For this purpose, the evaluation potential of Purslane (Portulaca oleracea) and Reed Yumak (Festuca arundinacea) plants at different salt concentrations by phytoremediation method was investigated. In the study, 4 different salt (NaCl) concentrations $(0,75,150$ and $200 \mathrm{mM})$ were applied to ensure soil salinity. In the study, plant height, plant dry weight and fresh weight parameters were measured. Electrical conductivity (EC), exchangeable sodium percentage (ESP), cation exchange capacity (CDC) properties were investigated in the soil before and after harvest. Considering the plant height, fresh weight and dry weight values, it was observed that the plant height of the cane ball plant increased by $6.33 \%$, the plant dry weight was $5.05 \%$ and the plant fresh weight $(11.12 \%)$ decreased. In the purslane plant, the plant height decreased by $39.1 \%$, the fresh and dry weight of the plant increased by $45 \%$
\end{abstract}

\footnotetext{
* Sorumlu Yazar: hasaner@bingol.edu.tr
} 
and $42.11 \%$. In the study consisting of two different plant groups, EC, ESP and CDC readings were performed in saline soil before planting and after harvesting. A decrease was observed in both plants. As a result of the calculations, it was determined that the cane ball plant decreased the EC and ESP values more than the purslane plant. Considering the CDC values, it was calculated that there were no significant changes for all applications. As a result of the research, both plants can be seen as plants that can be preferred in the phytoremediation method, which is considered in addition to other methods used in the reclamation of saline soils..

Keywords: Phytoremediation, Saline soils, Portulaca oleracea, Festuca arundinacea, Green breeding

\section{Giriş}

Toprak tuzluluğu yarı ve kurak bölgelerde tarımsal üretkenlik ve sürdürülebilirlik üzerinde ciddi olumsuz etkileri olan önemli bir çevresel faktör olarak görülmektedir (Shereen vd. 2016). Tuzluluk doğal süreçler veya aşırı sulama ve gübreleme sonucu toprak çözeltisi içerisinde toplam çözünmüş tuz konsantrasyonunun artması olarak ifade edilmektedir (Machado ve Serralheiro 2017). Birleşmiş Milletler Çevre Programı, dünyadaki tarım arazilerinin yaklaşık \%20'sinin ve ekili alanların $\% 50$ 'sinin tuz stresi altında olduğunu tahmin etmektedir (Ravindran ved. 2007). Sulanabilir tarım alanlarının yaklaşık \%20'si tuzluluktan etkilenmiş ve tarımsal üretim önemli derecede azalmıştır (Qadir vd. 2014). Dünya tarım arazilerinin sınır değerlerine ulaştığı dikkate alındığında tuzlu topraklar gibi sorunlu arazilerin islah edilerek tekrar tarıma kazandırılması önem teşkil etmektedir (Angın 2014). Tuzlu toprakların ıslahında yıkama, drenaj, derin sürüm, kumlama, kimyasal 1slah malzemeleri vb. gibi günümüzde birçok yöntem mevcuttur (Chhabra 2017). Bu yöntemlerin maliyetli olması, uzun sürmesi ve kimyasal ıslah işlemlerinde, tuzluluğun giderilmesi sırasında uygulanacak yıkama suyunun sürdürülebilir su kaynaklarının kullanımını daha etkin kullanmak amacıyla ıslah işlemleri için yeni yöntemler arayışına gidilmesi gerekmektedir.

Fitoremediasyon, tuzlu toprakların ıslahı için son zamanlarda araştırması yapılan bir yöntem olarak karşımıza çıkmaktadır (Han 2013; Karakas 2016; Er vd. 2021). Bitki ile 1slah olarak da adlandırılan fitoremediasyon, toprakta bulunan fazla tuzların bitkiler kullanılarak giderilmesi olarak tanımlanmaktadır (Qadir 2007; Shmaefsky 2020). Fitoremediasyon yöntemi ile tuzlu toprakların iyileştirilmesi işleminde sslah amacıyla halofit bitkilerin kullanılması olumlu açıdan daha etkin olduğu düşülmektedir (Nouri vd. 2017). Halofit bitkiler tuza dayanımı yüksek bitkiler olarak bilinmektedir. Bu bitkiler tuzlu koşullarda yetiştirilebilir ve tuzları dokularında biriktirerek fitoremediasyona yardımcı oldukları düşünülmektedir (Hasanuzzaman vd. 2014).

Bu çalışmada tuzlu toprakların fitoremediasyon yöntemi ile tekrardan ekonomik olarak üretken hale getirebilmeyi ve tuzluluğun verdiği olumsuz sebeplerden dolayı herhangi bir bitki deseni bulunmayan arazilerin toprak erozyonu ve çölleşmeyi azaltmak amacıyla halofit bitkilerin yetiştirilme potansiyeli ve kullanım olanaklarının değerlendirilmesi amaçlanmaktadır.

\section{Materyal ve Metot}

Araştırma 2021 yılında Bingöl Üniversitesi Ziraat Fakültesi Tarımsal Uygulama ve Araştırma Merkezi'ne bağlı seralarda saksı çalışması olarak yürütülmüştür. Denemede materyali olarak Semizotu (Portulaca oleracea) ve Kamışsı Yumak (Festuca arundinacea) bitkileri kullanılmıştır. Halofit türleri gölgede kurutulmuş ve $2 \mathrm{~mm}$ lik elekten geçirilmiş 8 litrelik saksılara yerleştirilmiştir. Toprak tuzluluğunu sağlamak amacıyla 0, 75, 150 ve $200 \mathrm{mM} \mathrm{NaCl}$ saf suda çözeltilerek toprağa verilmiştir. Çalışma tam şansa bağlı tesadüf desenine göre üç tekrarlamalı olarak 12 saksıda yürütülmüştür. Gelişme süresince bitkiler yaklaşık tarla kapasitesine getirilecek şekilde, ihtiyaç duyuldukça sulanmıştır.

Bitki fiziksel analizleri; Bitki boyu Rastgele seçilen bitkilerin toprakla temas ettiği kök boğazından uç kısmın uzunluğu ölçülerek aritmetik ortalaması alındı. Bitki yaş ağırlığı her bir saksıdan biçilerek hasat edilen otsu bitkiler tartılarak belirlendi. Bitki kuru ağırlığı her bir saksıdan alınan yaş örneklerinin 70 ${ }^{\circ} \mathrm{C}$ 'de ağırlıkları sabitleninceye kadar 48 saat kurutulmasından sonra tartılarak belirlendi.

Toprak analizleri; Bünye analizi: Toprakların kum, kil ve silt fraksiyonlarının oransal dağılımı Bouyoucos hidrometre yöntemi ile belirlenmiştir (Canbolat 2011). Toprak reaksiyonu $(\mathrm{pH})$ ve Toprak numunelerinin Elektriksel iletkenlik (EC) ölçümü EC metre ile ölçümleri gerçekleştirilmiştir. Toprak kireç miktarı $\left(\% \mathrm{CaCO}_{3}\right)$ analizi, Toprağın Scheibler kalsimetresinde seyreltik hidroklorik asitle reaksiyona tabi tutulması ile karbonatlardan çıkan CO2 gazının kapalı bir boruda tutularak hacminin ölçülmesi ve ölçülen değerlerin hesaplanması ile belirlenmiştir ( Allison ve Moodie 1965). Suda çözünebilir katyonları, Satürasyon çamurundan elde edilen süzüğün kullanılmasıyla AASP ile ölçülerek $\mathrm{Na}+, \mathrm{Ca}+2, \mathrm{Mg}+2$ ve $\mathrm{K}+$ gibi katyonlar belirlenmiştir. Katyon değişim kapasitesi (KDK), Na asetat ve Amonyum asetat çözeltileri ile iyon değiştirme esasına dayanan yöntem (atomik absorpsiyon spektro fotometre (AASP) ile hesaplanmıştır (Sumner ve Miller 1996). Değişebilir sodyum yüzdesi (ESP): Toprakların KDK sı ve değişebilir Na iyonlarından oransal ifadesi olarak belirlenmiştir. Deneme boyunca gözlemlenen parametreler tesadüf deneme desenine göre SPSS istatistik programında varyans analizine tabi tutulmuş ve ortalamalar arasındaki farklılıklar \%5 önem seviyesinde Duncan testi ile karşılaştırılmıştır.

\section{Araştırma Sonuçları ve Tartışma}

Kamışsı Yumak (Festuca arundinacea) ve Semiz otu (Portulaca oleracea) bitkilerinin 100 gün süren hasadın sonunda bitki yaş ağırlığı, bitki kuru ağırlığı ve bitki boyları ölçümleri gerçekleştirilmiştir. 
Tablo 1. Dört farklı tuzluluk seviyesi için Kamışsı Yumak (Festuca arundinacea) ve Semiz otu (Portulaca oleracea) bitkilerinin vejetatif ölçüm grafikleri

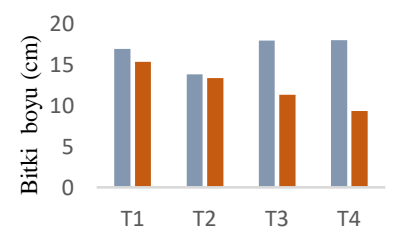

T1: $0 \mathrm{mM} \mathrm{NaCl}$ T3: $150 \mathrm{mM} \mathrm{NaCl}$

T2: $75 \mathrm{mM} \mathrm{NaCl}$ T4: $200 \mathrm{mM} \mathrm{NaCl}$

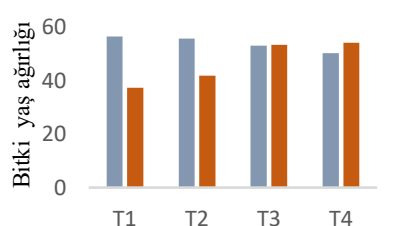

- Festuca arundinacea

- Portulaca oleracea

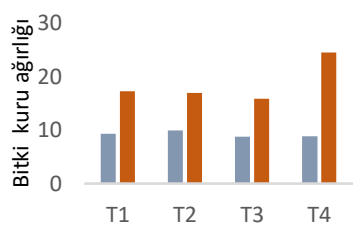

Tablo 2. Dört farklı tuzluluk seviyesi için Kamışsı Yumak (Festuca arundinacea) ve Semiz otu (Portulaca oleracea) bitkilerinin vejetatif ölçüm istatistikleri

\begin{tabular}{|c|c|c|c|c|c|c|c|c|c|c|c|c|}
\hline \multicolumn{7}{|c|}{ Kamışsı Yumak (Festuca arundinacea) } & \multicolumn{6}{|c|}{ Semiz otu (Portulaca oleracea) } \\
\hline \multirow{2}{*}{$\begin{array}{c}\text { Toprak } \\
\text { Tuz } \\
\text { Düzeyleri }\end{array}$} & \multicolumn{2}{|c|}{ Bitki boyu } & \multicolumn{2}{|c|}{$\begin{array}{l}\text { Bitki kuru } \\
\text { ağırlığ } 1\end{array}$} & \multicolumn{2}{|c|}{$\begin{array}{l}\text { Bitki yaş } \\
\text { ağırlığı }\end{array}$} & \multicolumn{2}{|c|}{ Bitki boyu } & \multicolumn{2}{|c|}{$\begin{array}{l}\text { Bitki yaş } \\
\text { ağırlığ }\end{array}$} & \multicolumn{2}{|c|}{$\begin{array}{c}\text { Bitki kuru } \\
\text { ağırlığg }\end{array}$} \\
\hline & $\mathrm{N}$ & Ort. & $\mathrm{N}$ & Ort. & $\mathrm{N}$ & Ort. & $\mathrm{N}$ & Ort. & $\mathrm{N}$ & Ort. & $\mathrm{N}$ & Ort. \\
\hline $\mathrm{T} 1$ & 3 & $16.9 \mathrm{a}$ & 3 & $9.29 \mathrm{a}$ & 3 & $56,37 \mathrm{a}$ & 3 & $15.33 \mathrm{a}$ & 3 & $37.23 \mathrm{a}$ & 3 & $17.19 \mathrm{a}$ \\
\hline $\mathrm{T} 2$ & 3 & $13.8 b$ & 3 & $9.88 \mathrm{a}$ & 3 & $55,6 \mathrm{a}$ & 3 & $13.33 b$ & 3 & $41,7 \mathrm{a}$ & 3 & $16,93 \mathrm{a}$ \\
\hline $\mathrm{T} 3$ & 3 & $17.96 \mathrm{c}$ & 3 & $8.77 \mathrm{~b}$ & 3 & $52,92 b$ & 3 & $11.33 \mathrm{c}$ & 3 & $53,2 \mathrm{~b}$ & 3 & $15,83 b$ \\
\hline $\mathrm{T} 4$ & 3 & $17.97 \mathrm{c}$ & 3 & $8.82 \mathrm{~b}$ & 3 & $50,1 \mathrm{~b}$ & 3 & $9.33 \mathrm{~d}$ & 3 & $54 \mathrm{~b}$ & 3 & $24.43 \mathrm{c}$ \\
\hline
\end{tabular}

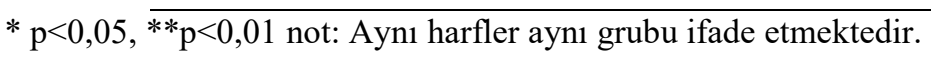

Tablo 2'e göre tuz konsantrasyonları ile bitki boyu, bitki kuru ağırlığı ve bitki yaş ağırlığı arasında ilişki anlamlı bulunmuştur $(\mathrm{P}<0.05)$. Kamışs yumak bitki boyu T3 ve T4 uygulamalarında aynı grupta yer almış olup T1 ve T2 uygulamalarında farklılaşmaktadır. Bitki kuru ağırlığı ve bitki yaş ağırlığı T1-T2 ve T3-T4 uygulamalarında aynı grupta yer almıştır. Semiz otu bitkisine bakıldığında bitki boyu bütün uygulamalarda farklı grupta yer almıştır. Bitki yaş ağırlığı T1-T2 ve T3-T4 uygulamalarında aynı grupta yer almıştır. Bitki kuru ağırlığı ise $\mathrm{T} 1$ ve $\mathrm{T} 2$ uygulamaları ayn $\mathrm{T} 3$ ve $\mathrm{T} 4$ uygulamaları farklı bulunmuştur. Bitki yaş ağırlığı incelendiğinde T4 uygulamasının T1 uygulamasına göre \% 46'lık önemli bir artışın geldiği gözlemlenmiş̧ir.

Topraklarda yapılan analizler sonucu elde edilen toprağa ait genel özellikler Tablo 3'de verilmiştir. İki farklı bitki grubundan oluşan çalışmada bitkilerin ekiminden önce ve hasatlarından sonra tuzlu toprakta EC okumaları gerçekleştirilmiştir. Her iki bitkide de düşüş gözlemlenmiştir. Kamışsı yumak bitkisi T2 uygulamasında $7.09 \mathrm{dS} / \mathrm{m}$ iken $2.1 \mathrm{dS} / \mathrm{m}$ (\% 70 azalış), T4 uygulamasında $13.8 \mathrm{dS} / \mathrm{m}$ iken $4.2 \mathrm{dS} / \mathrm{m}$ (\% 69.5 azalış) ile en önemli düşüşler hesaplanmıştır. Semizotu bitkisinde ise T3 uygulamasında $10.09 \mathrm{dS} / \mathrm{m}$ iken $4.3 \mathrm{dS} / \mathrm{m}$ (\% 57.38 azalış), T4 uygulamasında $13.8 \mathrm{dS} / \mathrm{m}$ iken $5.5 \mathrm{dS} / \mathrm{m}$ (\% 60.1 azalış) ile en önemli düşüşler hesaplanmıştır (Tablo 4). Hesaplamalar neticesinde kamışsı yumak bitkisi, semiz otu bitkisine göre EC değerlerini daha fazla azalttığı belirlenmiştir.

Tablo 3. Araştırmada kullanılan toprağa ait genel özellikler

\begin{tabular}{|c|c|c|c|c|c|c|c|}
\hline \multicolumn{4}{|c|}{ Tekstür(\%) } & \multirow[b]{2}{*}{ pH } & \multirow{2}{*}{\multicolumn{2}{|c|}{$\begin{array}{c}\mathrm{K}_{2} \\
\mathbf{O} \\
\mathbf{( k g} \\
/ \mathbf{d a} \\
\mathbf{)}\end{array}$}} & \multirow[b]{2}{*}{$\begin{array}{c}\mathrm{P}_{2} \mathrm{O}_{5} \\
(\mathrm{~kg} / \mathrm{d} \\
\text { a) }\end{array}$} \\
\hline Kil & Silt & Kum & Sinıf & & & & \\
\hline 58 & 23 & 19 & killi & 7.5 & 1.17 & $\begin{array}{l}75 \\
88\end{array}$ & 3.59 \\
\hline
\end{tabular}

İki farklı bitkinin yetiştirildiği toprakta yapılan ekim öncesi ve hasat sonrası Değişebilir sodyum yüzdesi değerleri incelendiğinde iki bitkide ESP değerlerini azalttığı görülmüştür. Kamışsı yumak bitki T4 uygulaması değişebilir sodyum yüzdesini \% 11.7'den 8.7'ye, T1 uygulaması ise \%13,81'den 10,36'ya düşürerek en önemli azalışlar gözlemlenmiştir. Semizotu bitkisinde ise T2 uygulamas $\% 13.54$ 'den 10.58 'e, T3 uygulamas1 \%13.19'dan 10.34'e düşürerek en önemli azalışlar gözlemlenmiştir (Tablo 5). Hesaplamalar sonucunda iki bitki kıyasladığında kamışsı yumak bitkisinin ESP değerlerini daha fazla düşürdüğü belirlenmiştir. İki bitkininde KDK değerlerine bakıldığında bütün uygulamalar için önemli değişimlerin olmadığı hesaplanmıştır (Tablo 5). 
Tablo 4. Hasat sonrasında toprakların gösterdikleri elektiriksel iletkenlik (EC) değerleri.

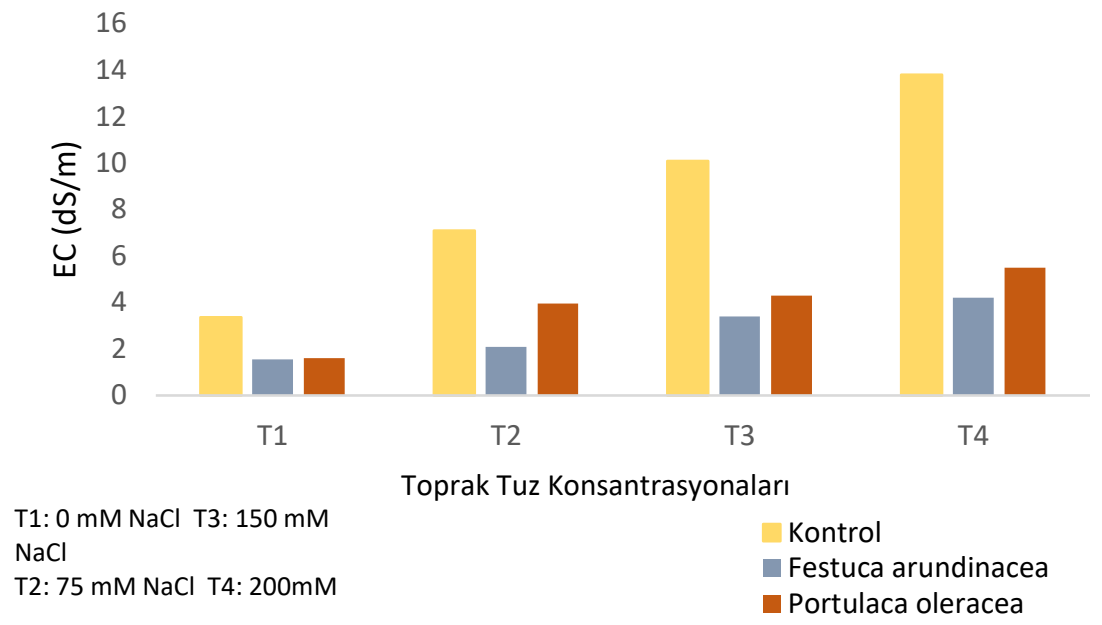

Tablo 5. Hasat sonrasında toprakların gösterdikleri Değişebilir Sodyum Yüzdesi (ESP) ve Katyon Değişim Kapasiteleri (KDK)

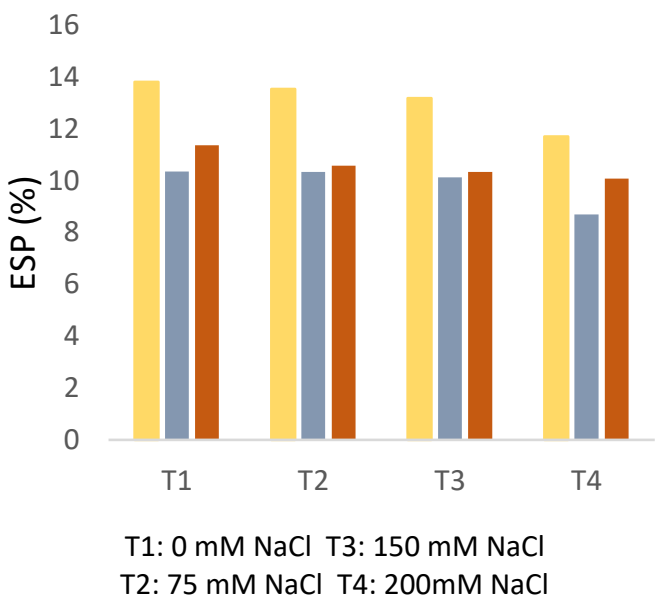

T2: $75 \mathrm{mM} \mathrm{NaCl}$ T4: $200 \mathrm{mM} \mathrm{NaCl}$

Akhter ve ark., (2003) tuzlu-sodik toprakların 1slahında baraj otu (Leptochloafusca L.) bitkisini kullanmıştır. Araştırma 5 yıl boyunca gözlemlenmiş ve araştırma sonucu olarak baraj otunun tuzlu sodik toprakların elektiriksel iletkenlik (EC) ve sodyum adsorbsiyon oranı (SAR) değerleri üzerine olumlu bir etki yaptı̆̆ belirtilmiștir. Ayrıca Akhter ve ark., (2004) fitoremediasyon üzerine yaptığ 1 çalışmasında tuzlu-sodik topraklarda baraj otu (Leptochloafusca L.) bitkisini yetiştirmişlerdir. Çalışma sonucunda toprakların kullanılabilir su tutma kapasitesi, hidrolik iletkenliği ve toprağın strüktürel dayanımı üzerine olumlu sonuçlar belirlemişlerdir. Ravindran ve ark., (2007), fitoremediasyon yöntemi üzerine yaptığı araştırmada Clerodendroninerme Gaertn., Sesuvium portulacastrum L., Heliotropium curassavicum L., Suaedemaritima Dum., Ipomoea pes-caprae Sweet., halofit bitkileri $0,30,60,90$ ve 120 gün boyunca yetiştirilmiş ve uygulama periyodu boyunca toprağın elektiriksel iletkenlik (EC) ve sodyum adsorbsiyon oranı (SAR) değerlerinde önemli derecede olumlu değişimler olduğu ifade edilmiştir. Karakaş (2017) yürüttüğü çalışmada farklı tuz seviyelerine sahip topraklarda (T1: $0.9 \mathrm{dS} / \mathrm{m}, \mathrm{T} 2: 4.2 \mathrm{dS} / \mathrm{m}, \mathrm{T} 3$ : $7.2 \mathrm{dS} / \mathrm{m}$ ve T4: $4.1 \mathrm{dS} / \mathrm{m}$ ) yetiştirilen Salsola soda ve Portulacaoleracea bitkilerin, toprakların EC değerlerini önemli derecede azaltmış olup, kimyasal ıslah malzemeleri ile yapılan

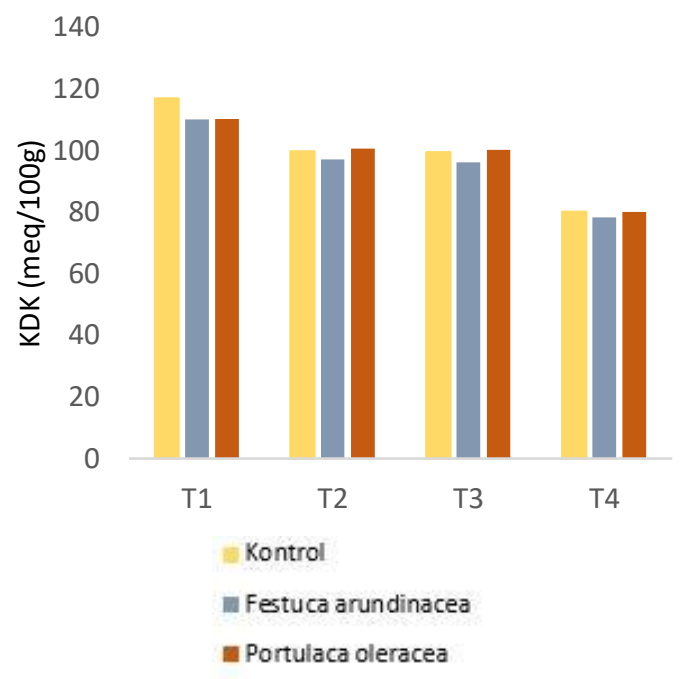

uygulamalara alternatif bir yöntem olabileceği belirtilmiştir. Li ve ark., (2019) tuzlu toprakların iyileştirilmesi üzerine yaptığ çalışmada Suaeda salsa ve Trichoderma asperellum bitkilerinin fitoremediasyon tekniği olarak kullanılabileceği belirtmişlerdir.

\section{Sonuç}

Tuzlu toprakların artması dünya genelinde büyük sorunlardan biri olup tarımsal üretimi olumsuz etkilemektedir. Dünya nüfusunun hızlı bir şekilde artması tarıma ve gıdaya olan ihtiyacı da önemli derece de artırmaktadır. Bu bağlamda yaptığımız araştırmamızda tuzlu toprakların fitoremediasyon yöntemiyle iyileştirilmesinin etkisini belirlemek için 2 farklı bitki ve 4 farklı tuz konsantrasyonu uygulanmıştır. Çalışmada bitkinin bitki boyu, bitki yaş ağırlığı ve kuru ağırlığına ölçülmüşs olup, toprakta ise elektriksel iletkenlik (EC), değişebilir sodyum yüzdesi (ESP), katyon değişim kapasitesi (KDK) değerleri analiz edilmiştir. Analizler neticesinde yetiştirilen her iki bitkide tuzlu toprakların ıslahında kullanılan diğer yöntemlere ek olarak düşünülen fitoremediasyon yönteminde tercih edilebilecek bitkiler olarak görülebilmektedir. 


\section{Kaynakça}

Chhabra, R. (2017). Soil salinity and water quality. Routledge.

Akhter, J.,Mahmood, K., Malik, K. A., Ahmed, S., \& Murray, R, (2003). "Amelioration of a saline sodic soil through cultivation of a salt-tolerantgrass", Leptochloafusca. Environ. Conserv., 30,.168-174.

Akhter, J.,Murray, R., Mahmood, K., Malik, K.A., Ahmed, S, (2004). Improvement of degraded physical properties of a saline-sodic soil by reclamation with kallar grass (Leptochloafusca). Plant and Soil. 258, 207-216.

Allison, L.E., Moodie C.D., (1965). Carbonate, In: C.A. Black (Ed.), Methods Of Soil Analysis, Part 2, Agronomyno. 9, 1379-1400. USA

Angın, İ. (2014). Tuzlu-Sodik ve Sodik Toprakların Islahına Farklı Bir Yaklaşım: Yeşil Islah. Erzincan Üniversitesi Fen Bilimleri Enstitüsü Dergisi, 3(1), 103-116.

Canbolat, M. Y., (2011). Toprağa H2o2 Muamelesinin Day ve Bouyoucos Hidrometre Yöntemlerinde Dane Büyüklük Dağılımı Üzerine Etkisi. Atatürk Üniversitesi Ziraat Fakültesi Dergisi, 25(1).

Er, H., Meral, R., \& Kuşlu, Y. (2021). Tuzlu Toprakların Halofit Bitkiler Kullanarak Fitoremediasyon Yöntemiyle İyileştirilmesi Olanaklarının Değerlendirilmesi. Turkish Journal of Scientific Reviews, 14(2), 101-110.

Han, L., Liu, H., Yu, S., Wang, W., \& Liu, J. (2013). Potential application of oat for phytoremediation of salt ions in coastal saline-alkali soil. Ecological engineering, 61, 274-281.

Hasanuzzaman, M., Nahar, K., Alam, M.M., Bhowmik, P.C., Hossain, M.A., Rahman, M.M., Prasad, M.N.V., Ozturk, M., Fujita, M., (2014). Potential use of halophytes to remediate saline soils. Biomed. Res. Int. 2014, 589341.

Karakas S., Çullu MA., \& Dikilitaş M, (2017). “Comparison of two halophyt especies (Salsola soda and Portulacaoleracea) for salt removal potential under different soil salinity conditions", Turk J AgricFor, vol. 41, pp.183190.

Karakas, S., Cullu, M. A., Kaya, C., \& Dikilitas, M. (2016). Halophytic companion plants improve growth and physiological parameters of tomato plants grown under salinity. Pak. J. Bot, 48(1), 21-28.

Li, X.,Zhang, X., Wang, X., Yang, X., Cui, Z, (2019). Bioaugmentation-assisted phytoremediation of lead and salinity co-contaminated soil by Suaeda salsa and Trichodermaa sperellum. Chemosphere, 224, 716-725.

Machado, R. M. A., \& Serralheiro, R. P. (2017). Soil salinity: effect on vegetable crop growth. Management practices to prevent and mitigate soil salinization. Horticulturae, 3(2), 30.

Nouri, H., Chavoshi Borujeni, S., Nirola, R., Hassanli, A., Beecham, S., Alaghmand, S., \& Mulcahy, D. (2017). Application of green remediation on soil salinity treatment: A review on halophytoremediation. Process Safety and Environment Protection, 107, 94-107.

Qadir M, Quillerou E, \& Nangia V, (2014), "Economics of saltinduced land degradation and restoration". Natural Resources Forum, vol. 38, pp.282-295.

Qadir, M., Oster, J. D., Schubert, S., Noble, A. D., \& Sahrawat, K. L. (2007). Phytoremediation of sodic and saline-sodic soils. Advances in agronomy, 96, 197-247.

Ravindran, K.C., Venkatesan, K., Balakrishnan, V., Chellappan, K.P., Balasubramanian, T, (2007). Restoration of saline land by halophytes for Indian soils. Soil Biology \& Biochemistry. 39, 2661-2664.
Shereen, A., Ansari, R., Raza, S., Shirazi, M. U., Khan, M. A., \& Mumtaz, S. (2016). Effect of transpiration rate on sodium accumulation in rice (Oryza sativa L.) grown under saline conditions. Pak. J. Bot, 48(1), 47-51.

Shmaefsky, B. R. (2020). Principles of Phytoremediation. Phytoremediation: In-situ Applications.

Sumner, M.E. Miller, W.P., (1996). Cation Exchange Capacity and Exchange Coefficients. In. D.L. Sparks et. al., (Ed.), Methods of Soil Analysis Part 3: Chemical Methods. SSSA Book Series No: 5. Am. Soc. of Agronomy and Soil Sci. Soc. Of Am. Inc. Publisher, Madison, Wisconsin USA. pp.12011230 . 